\title{
Effects of Individual and Work-related Factors on Incidence of Shoulder Pain in a Large Working Population
}

\author{
Julie Bodin ${ }^{1}$, Catherine HA${ }^{2}$, Céline SÉrazIN ${ }^{1}$, Alexis Descatha ${ }^{3}$, \\ Annette LECLERC ${ }^{3}$, Marcel GoldBerG ${ }^{3}$ and Yves RoQuelaure ${ }^{1}$
}

${ }^{1}$ LUNAM Université, Université d'Angers, Laboratoire d'ergonomie et d'épidémiologie en santé au travail (LEEST), France, ${ }^{2}$ Département santé travail, Institut de veille sanitaire (DST-InVS), France and ${ }^{3}$ INSERM, U1018, France

\begin{abstract}
Effects of Individual and Work-related Factors on Incidence of Shoulder Pain in a Large Working Population: Julie Bodin, et al. LUNAM Université, Université d'Angers, Laboratoire d'ergonomie et d'épidémiologie en santé au travail (LEEST), France-Objectives: The aim of this study was to assess the effects of individual and work-related factors on the incidence of shoulder pain in a large French working population. Methods: A total of 3,710 workers of a French region were randomly included in a cross-sectional study between 2002 and 2005 . They completed a self-administered questionnaire about musculoskeletal symptoms, individual factors and exposure to work constraints. In 2007, 2,332 responded to a follow-up questionnaire. The Nordic questionnaire was used both times to assess shoulder pain during the preceding 7 days. Associations between incident shoulder pain and individual and work-related factors at baseline were studied by multivariate logistic regression for both genders. Results: A total of 946 men and 709 women without shoulder pain at baseline were eligible for the analyses. At follow-up, 105 men (11.1\%) and 145 women $(20.5 \%)$ reported shoulder pain. For men, age (OR 3.3, 95\% Cl, 1.7-6.5 for $\geq 50 \mathrm{yr}$ ), working with arms above the shoulder $(1.5 ; 1.0-2.3)$ and high perceived physical exertion $(1.6 ; 1.0-2.5)$ increased the risk of incident shoulder pain. For women, the factors associated with incident shoulder pain were age (2.9; $1.5-5.8$ for $\geq 50 \mathrm{yr})$, obesity $(2.5 ; 1.4-4.5)$, temporary employment $(2.1 ; 1.1-3.7)$, high perceived physical exertion $(2.2 ; 1.4-3.5)$ and low decision latitude (1.6; 1.0-2.3). Conclusion: Age was the strongest predictor of incident shoulder pain in both genders. BMI and biomechanical and psychosocial factors were also identified as risk factors, whereas no factor related to
\end{abstract}

Received Dec 14, 2011; Accepted Apr 16, 2012

Published online in J-STAGE May 29, 2012

Correspondence to: J. Bodin, Laboratoire d'Ergonomie et d'Epidémiologie en santé au travail, Faculté de Médecine, Rue Haute de Reculée, 49045 ANGERS Cedex, France (e-mail: julie. bodin@univ-angers.fr) work organization remained in the final models. (J Occup Health 2012; 54: 278-288)

Key words: Incidence, Individual factors, Shoulder pain, Work-related factors

Musculoskeletal disorders (MSDs) and musculoskeletal complaints are a major cause of morbidity at work in Europe and North America and the leading causes of compensated occupational diseases in several European countries ${ }^{1}$. The body regions most often affected are the lower back, the neck and the shoulders.

Shoulder pain (SP) is common both in the general population, with 1-year prevalence rates between 7 and $47 \%^{2)}$, and in the working population ${ }^{3)}$. A systematic review of occupational risk factors for shoulder pain in $2000^{4}$ included 29 studies: 26 cross sectional designs, 3 case-control studies and no prospective studies. In the past ten years, additional papers on the incidence of SP have been published $^{2,5-12)}$. However, neck and shoulder pain were not always distinguished ${ }^{7,8,10-12)}$. Some of these studies focused on the general working population ${ }^{5,7,8)}$, but the majority surveyed specific populations, such as manual workers ${ }^{6,10)}$, nurses ${ }^{2,11)}$ and newly employed workers ${ }^{9}$. A systematic review of recent longitudinal studies in 2010 ${ }^{13)}$ reported that the main risk factors found to have reasonable evidence supporting their causal relationship with shoulder pain were heavy physical load and psychosocial factors (high level of distress, monotonous work and low job control) on the basis of only three studies ${ }^{5,6,9)}$. It has been shown in other studies that biomechanical factors, such as repetitive movements, arm above the shoulder and pushing or pulling were also associated with incident $\mathrm{SP}^{7,10,11)}$. The role of individual factors in incident SP was rarely studied or was not the main focus of studies $^{14)}$. 
We used data gathered between 2002 and 2005 and between 2007 and 2009 from the prospective surveillance program for MSDs implemented by the French Institute for Public Health Surveillance in the Pays de la Loire region. The aim of this study was to assess the relative impact of individual, biomechanical, work organization and psychosocial factors on the incidence of SP in a large working population exposed to various levels of shoulder constraints.

\section{Materials and Methods}

\section{Study population}

This prospective study was based on two successive surveys of a large sample of workers in the Pays de la Loire region in France. The region contains 5.6\% of the French working population, and its diversified socioeconomic structure is close to that of France as a whole $^{1)}$.

All French salaried workers, including temporary and part-time workers, undergo a mandatory annual health examination by an occupational physician (OP) in charge of the medical surveillance of a group of companies. Between April 2002 and April 2005, a total of 83 OPs, representing $18 \%$ of OPs of the region, volunteered to take part in the study. They were representative of the region's OPs in terms of medical practice, working time and geographic and economic sectors covered ${ }^{3}$.

Subjects were selected at random, following a two-stage sampling procedure: first, the research team chose 15-45 half-days of scheduled examinations for each OP. Next, using random sampling tables, each OP selected 1 out of 10 workers from the schedule on the half-days of worker examinations considered. Fewer than $10 \%$ of the selected workers were not included (no shows, refusals and duplications). Workers completed a self-administered questionnaire about their musculoskeletal symptoms and their working conditions and then underwent a physical examination performed by the OP. A total of 3,710 workers $(2,161$ men $(58.2 \%)$ with a mean age of $38.5 \mathrm{yr}$, standard deviation $10.4 \mathrm{yr}$, and 1,549 women (42.8\%) with a mean age of $38.9 \mathrm{yr}$, standard deviation $10.3 \mathrm{yr}$ ) were included (out of 184,600 under surveillance by the $83 \mathrm{OP}, 2.0 \%)$. Women were slightly underrepresented in the sample ( $42 \%$ vs. $47 \%$ in the region). Overall, the distribution of occupations in the study sample was close to that of the regional workforce, except for the occupations not surveyed by the OPs (e.g., shopkeepers and independent workers $)^{1,3)}$. Subjects worked mainly in the service industry $(58.6 \%)$ and the manufacturing industry $(33.7 \%)$ sectors, and more rarely in the construction (5.8\%) and agriculture (1.9\%) sectors. Men were mainly skilled and unskilled blue collar workers $(56.0 \%)$, associate professionals and technicians $(25.0 \%)$ and managers and professionals (9.7\%). Most women were low-grade white collar workers $(51.7 \%)$, skilled and unskilled blue collar workers $(24.4 \%)$ and associate professionals and technicians $(18.7 \%)$.

In 2007, a follow-up questionnaire was mailed to subjects. In the case of non-response, they were sent two successive reminder letters with the self-administered questionnaire. If their address was unknown, the new address was sought by contacting either their OP or the French public postal services. For workers who had not returned the self-administered questionnaire in 2007, the OPs were asked to pass on the questionnaire to the workers during a regular health examination in 2008 and 2009.

\section{Shoulder pain}

The outcome variable was incident SP.

SP during the preceding 7 days was assessed at baseline and at follow-up using a modified version of the standardized Nordic-style questionnaire ${ }^{15-19)}$. The subjects were asked if they had experienced any ache, discomfort, pain or numbness in the shoulders. A mannequin was used to indicate the anatomical areas including the shoulder region, as distinct from the neck region.

Subjects free from SP at baseline were those without SP during the preceding 7 days at baseline and without SP for more than 8 days during the preceding 12 months at baseline. "Incident cases" were defined as subjects free from SP at baseline who stated they had SP during the 7 days preceding the second questionnaire. Subjects with rotator cuff syndrome diagnosed by an OP at baseline were therefore excluded.

\section{Potential risk factors}

The potential risk factors were assessed at baseline. Variables were divided into four groups: individual factors, organizational factors, biomechanical factors and psychosocial factors.

1) Individual factors

In the self-administered questionnaire, workers were asked about their age, height and weight. Age was divided into four categories $(<30,30-39,40-49$ and $\geq 50 \mathrm{yr}$ ). BMI was calculated as $\mathrm{kg} / \mathrm{m}^{2}$ and divided into three categories $\left(<25,25-30\right.$ and $\left.\geq 30 \mathrm{~kg} / \mathrm{m}^{2}\right)$. Upper-extremity MSDs (UE-MSDs) at baseline was defined as the diagnosis of at least one of the following UE-MSDs: lateral epicondylitis, ulnar tunnel syndrome, carpal tunnel syndrome, De Quervain's disease and flexor-extensor peritendinitis or tenosynovitis of the forearm-wrist region. To establish a diagnosis, a standardized physical examination was performed by the OP using a clinical procedure based on the criteria document for evaluating the work- 
relatedness of UE-MSDs ${ }^{20)}$.

2) Work-related factors

Work status and exposure to work-related risk factors were assessed with the self-administered questionnaire including information on the characteristics of the job and tasks and work organization:

- The organizational factors studied were time constraints (paced work, work pace dependent on automatic rate, other technical organization, quantified targets, customers' demand, permanent controls or surveillance), job/task rotation, overtime hours, high visual demand, lack of prior information regarding the amount of work to be done each day, variable weekly working time, working with temporary workers and temporary employment. Responses to the questions were categorized as yes/ no.

- The response categories for biomechanical factors were presented on a 4-level Likert-type scale, as follows: never or practically never, rarely (less than $2 \mathrm{~h}$ per day), often ( 2 to $4 \mathrm{~h}$ per day) and always (more than $4 \mathrm{~h}$ per day). Several factors were defined and quantified according to a European consensus $^{20)}$. The risk factors used for the criteria for the shoulder region were repetitiveness of tasks ( $\geq 4 \mathrm{~h} /$ day), working with arms abducted ( $\geq 2 \mathrm{~h} /$ day) and holding a hand behind the trunk ( $\geq 2 \mathrm{~h} /$ day). Workers were defined as being at risk of working with arms above the shoulder if they responded with "rarely", "often" or "always". Additional variables, known or suspected to be risk factors, were considered: use of vibrating handtools ( $\geq 2 \mathrm{~h} /$ day) and exposure to cold temperature ( $\geq 4 \mathrm{~h} /$ day). Perceived physical exertion was assessed using the Rating Perceived Exertion Borg scale (20-RPE) graduated from 6 ("very, very light") to 20 ("maximum exertion") ${ }^{21-23)}$. Workers at risk (i.e., high perceived physical exertion) were dichotomized at the third quartile ( $\geq 15$ for men and $\geq 14$ for women).

- Psychosocial work factors (high psychosocial demand, low decision latitude, low supervisor support and low coworker support) were assessed according to the validated French version of the Karasek Job Content Questionnaire. Workers at risk were dichotomized using the median scores of the national French SUMER study ${ }^{24}$.

\section{Statistical analysis}

Analyses were performed separately for men and women to take into account possible differences in exposure to work constraints between genders ${ }^{25)}$. Bivariate associations between SP and the risk factors were studied by Chi-squared or Fisher's exact tests. Risk factors with a $p$-value $<0.20$ were placed in a multivariable model by groups of variables (individual factors, organizational factors, biomechanical factors and psychosocial factors). Manual backward multivariate logistic regression models were then applied for each group of variables in order to avoid collinearity between exposure variables in the final model (age was forced into the models). Nonsignificant variables $(p \geq 0.10)$ were excluded after this stage. The remaining factors were entered into a final global multivariate logistic regression model, and manual backward selection retained only significant variables with a $p$-level $<0.05$. In the manual backward multivariate logistic regression, all possible confounding effects of relevant variables were checked individually, and if a change in the beta coefficients of $\geq 15 \%$ occurred when a variable was deleted, the variable was considered to be a confounder and forced into the final model. The goodness of fit of the logistic model was determined by the Hosmer-Lemeshow test.

To test the effects of a change of job during followup, a composite variable was included in each of the final models obtained in the previous analysis. The variable created had three categories (no change, change of job during follow-up and not working at the time of the second questionnaire).

All analyses were performed with the SAS statistical software package (version 9.2: SAS Institute Inc., Cary, NC, USA).

Each subject provided informed written consent to participation in this study at baseline, and the study received approval from France's National Committee for Data Protection (Commission Nationale de l'Informatique et des Libertés), first in 2001 and then again in 2006.

\section{Results}

\section{Participation at follow-up}

Between 2007 and 2009, 233 (6.3\%) subjects could not be contacted because their addresses were unknown $(n=215)$ or because they were deceased $(n=18)$. Among the contactable subjects, 1,145 did not respond, and finally, a total of 2,332 subjects $(67.1 \%)$ filled out the second self-administered questionnaire $(96.9 \%$ filled out the second self-administered questionnaire in 2007) (Fig. 1).

We compared the characteristics of the responding workers to the non-responders (whatever the reason of their lack of participation). Women more often participated than men $(65.8 \%$ vs. $60.8 \%)$. Participation increased with age until $54 \mathrm{yr}$ (from $49.2 \%$ under $30 \mathrm{yr}$ to $72.8 \%$ between 50 and $54 \mathrm{yr}$ and $64.6 \%$ over $55 \mathrm{yr}$ ) and with the length of service at baseline (from $50.5 \%$ under one year to $68.1 \%$ over $10 \mathrm{yr}$ ) for both genders. Temporary workers were more often lost to follow-up $(48.4 \%$ vs. $64.8 \%)$. More male white 


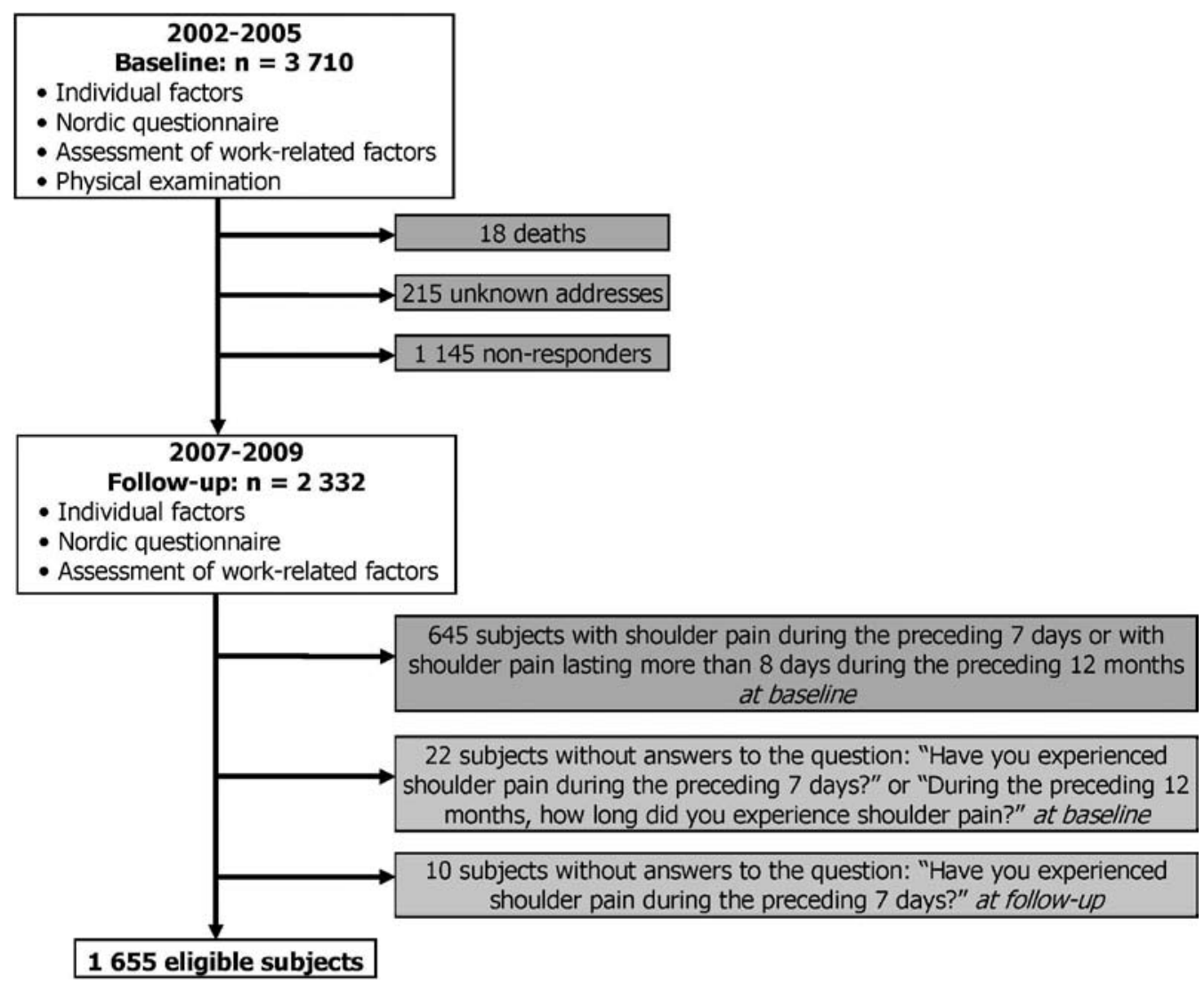

Fig. 1. Flowchart of participant eligibility for analyses of incident shoulder pain.

collar workers participated $(65.9 \%)$ compared with male unskilled workers $(52.8 \%)$. More men with UE-MSDs at baseline (73.3\% vs. $59.2 \%)$, as well as men with SP during the 7 preceding days at baseline $(68.9 \%$ vs. $59.1 \%)$, participated. The latter three differences were not observed in women.

Among the 2,332 subjects, 645 reported SP during the preceding 7 days at baseline or lasting more than 8 days during the preceding 12 months at baseline, and 32 did not answer these questions at baseline or at follow-up. Finally, 1,655 subjects (946 men (57\%) and 709 women $(43 \%)$ ) were eligible for analysis of incidence of SP (Fig. 1).

\section{Study population at baseline}

Men were more often overweight than women. Occupational factors differed between men and women; men were more exposed to organizational (such as work pace dependent on quantified targets) and to some biomechanical factors (such as arms above the shoulder and use of vibrating handtools). However, women were more often exposed to high repetitiveness of tasks. Among psychosocial factors, women were also more exposed to low decision latitude (Table 1).

\section{Shoulder pain at follow-up}

At follow-up, 105 men (11.1\%) and 145 women $(20.5 \%)$ reported shoulder pain $(p<0.001)$. Of these, 38 men and 69 women reported pain intensity levels higher than 4 on a visual analog scale ranging from 0 to 10 . The right shoulder was involved in $44.2 \%$ of cases, and the left shoulder was involved in $28.1 \%$ of cases; both shoulders were involved in $27.7 \%$ of cases. A difference in incident SP was found between active and inactive men in 2007-2009 (10.4\% vs. $18.6 \%$, respectively, $p=0.026)$, but the difference was not significant after adjustment for age. No difference was observed in women. Among active subjects, there was no difference between those who changed job and those who did not $(14.7 \%$ vs. $14.8 \%$, respectively, $p=0.958$ ).

1) Results in men

Incident SP in men was associated with age, lack of prior information regarding the amount of work to be done each day, a high perceived physical exertion, arms above the shoulder and holding a hand behind the trunk, with a $p$-value $<0.20$. No psychosocial factors were associated with SP (Table 2). In the multivariate model, age increased the risk of incident SP. Working with a high perceived physical exertion 
Table 1. Baseline characteristics of the study population

\begin{tabular}{|c|c|c|c|c|c|}
\hline \multirow{2}{*}{ Baseline characteristics } & \multicolumn{2}{|c|}{ Men (n=946) } & \multicolumn{2}{|c|}{ Women $(n=709)$} & \multirow{2}{*}{$p^{*}$} \\
\hline & $\mathrm{n}$ & $\%$ & $\mathrm{n}$ & $\%$ & \\
\hline \multicolumn{6}{|l|}{ Personal factors and medical history } \\
\hline Age & & & & & 0.763 \\
\hline$<30$ & 198 & 20.9 & 149 & 21.0 & \\
\hline $30-39$ & 293 & 31.0 & 226 & 31.9 & \\
\hline $40-49$ & 280 & 29.6 & 217 & 30.6 & \\
\hline$\geq 50$ & 175 & 18.5 & 117 & 16.5 & \\
\hline BMI & & & & & $<0.001$ \\
\hline Underweight-normal $(<25)$ & 528 & 56.5 & 508 & 72.3 & \\
\hline Overweight (25-30) & 336 & 35.9 & 134 & 19.1 & \\
\hline Obesity ( $\geq 30)$ & 71 & 7.6 & 61 & 8.7 & \\
\hline Upper-extremity musculoskeletal disorders & 41 & 4.3 & 36 & 5.1 & 0.477 \\
\hline \multicolumn{6}{|l|}{ Occupational class and employment contract } \\
\hline Occupational class & & & & & $<0.001$ \\
\hline Managers, professionals, technicians & 382 & 40.4 & 182 & 25.8 & \\
\hline Low-level white collar & 81 & 8.6 & 372 & 52.7 & \\
\hline Skilled blue collar & 348 & 36.8 & 48 & 6.8 & \\
\hline Unskilled blue collar & 135 & 14.3 & 104 & 14.7 & \\
\hline Temporary employment & 77 & 8.2 & 83 & 11.8 & 0.014 \\
\hline \multicolumn{6}{|l|}{ Factors related to work organization } \\
\hline Paced work & 89 & 9.6 & 52 & 7.6 & 0.168 \\
\hline Work pace dependent on automatic rate & 93 & 10.0 & 48 & 7.0 & $\mathbf{0 . 0 3 3}$ \\
\hline Work pace dependent on other technical organization & 241 & 25.9 & 75 & 11.0 & $<0.001$ \\
\hline Work pace dependent on quantified targets & 488 & 52.1 & 257 & 37.6 & $<0.001$ \\
\hline Work pace dependent on demand of customers & 426 & 45.4 & 319 & 45.8 & 0.867 \\
\hline Work pace dependent on permanent controls or surveillance & 220 & 23.7 & 161 & 23.4 & 0.918 \\
\hline Job/task rotation ( $\geq 1$ job rotation per week) & 341 & 37.9 & 225 & 33.8 & 0.091 \\
\hline Overtime hours & 636 & 68.0 & 373 & 53.6 & $<0.001$ \\
\hline Work with temporary workers & 263 & 27.8 & 192 & 27.3 & 0.812 \\
\hline High visual demand & 172 & 18.3 & 123 & 17.6 & 0.732 \\
\hline Lack of prior information regarding the amount of work to be done each day & 123 & 13.1 & 25 & 3.5 & $<0.001$ \\
\hline Variable weekly working time & 542 & 57.4 & 342 & 48.8 & 0.001 \\
\hline \multicolumn{6}{|l|}{ Working postures and biomechanical constraints } \\
\hline High repetitiveness of tasks ( $\geq 4 \mathrm{~h} /$ day) & 179 & 19.0 & 194 & 27.6 & $<0.001$ \\
\hline Arms above the shoulder & 363 & 38.5 & 215 & 30.5 & 0.001 \\
\hline Arms abducted ( $\geq 2$ h/day) & 121 & 12.8 & 82 & 11.6 & 0.457 \\
\hline Holding hand behind the trunk ( $\geq 2 \mathrm{~h} /$ day) & 36 & 3.8 & 30 & 4.2 & 0.662 \\
\hline Use of vibrating handtools ( $\geq 2 \mathrm{~h} /$ day) & 159 & 16.8 & 19 & 2.7 & $<0.001$ \\
\hline Exposure to cold temperature ( $\geq 4$ h/day) & 68 & 7.2 & 26 & 3.7 & 0.002 \\
\hline \multicolumn{6}{|l|}{ Psychosocial factors at work } \\
\hline High psychological demand & 435 & 46.3 & 329 & 46.9 & 0.807 \\
\hline Low decision latitude & 398 & 42.6 & 404 & 57.7 & $<0.001$ \\
\hline Low supervisor support & 370 & 39.5 & 242 & 35.1 & 0.067 \\
\hline Low coworker support & 172 & 18.4 & 126 & 18.2 & 0.915 \\
\hline
\end{tabular}

*Comparison of baseline characteristics between men and women, $\chi^{2}$ test.

and working with arms above the shoulder were of borderline significance (Table 3 ).

2) Results in women

More factors were associated with incident SP in bivariate analyses in women. All the individual factors studied were significantly associated with incident SP, with a $p$-value $<0.20$. Temporary employment, paced work, work pace dependent on automatic rate, work pace dependent on other technical organization, work pace dependent on quantified targets, a high level of visual demand, working with high repetitiveness of tasks, working with a high perceived physical exertion, working with arms above the shoul- der, exposure to cold temperature, low decision latitude and low coworker support were associated with a high incidence of SP (Table 2). In the multivariate model, the strength of association was high for age. Associations were also found for obesity, temporary employment, high perceived physical exertion and low decision latitude (Table 3). Women in temporary employment were mainly low-level white collar (44.4\%) and unskilled blue collar workers $(32.1 \%)$. In the latter group, $38.5 \%$ had incident SP.

The reliability of the models was appropriate according to the Hosmer-Lemeshow test, with a $p$-value of 0.434 for men and 0.183 for women. 
Table 2. Incidence of shoulder pain in relation to individual, work organization, biomechanical and psychosocial factors

\begin{tabular}{|c|c|c|c|c|c|c|}
\hline \multirow[t]{2}{*}{ Baseline characteristics } & \multicolumn{3}{|c|}{ Men (n=946) } & \multicolumn{3}{|c|}{ Women $(n=709)$} \\
\hline & $\mathrm{n}$ & Incidence $(\%)$ & $p^{*}$ & $\mathrm{n}$ & Incidence $(\%)$ & $p^{*}$ \\
\hline \multicolumn{7}{|l|}{ Personal factors and medical history } \\
\hline Age & & & 0.001 & & & 0.014 \\
\hline$<30$ & 198 & 7.1 & & 149 & 14.1 & \\
\hline $30-39$ & 293 & 8.2 & & 226 & 17.3 & \\
\hline $40-49$ & 280 & 12.1 & & 217 & 24.4 & \\
\hline$\geq 50$ & 175 & 18.9 & & 117 & 27.4 & \\
\hline BMI & & & 0.542 & & & 0.001 \\
\hline Underweight-normal $(<25)$ & 528 & 10.2 & & 508 & 17.9 & \\
\hline Overweight $(25-30)$ & 336 & 12.5 & & 134 & 22.4 & \\
\hline Obesity $(\geq 30)$ & 71 & 12.7 & & 61 & 37.7 & \\
\hline Upper-extremity musculoskeletal disorders & & & $1.000^{+}$ & & & 0.005 \\
\hline No & 905 & 11.2 & & 673 & 19.5 & \\
\hline Yes & 41 & 9.8 & & 36 & 38.9 & \\
\hline \multicolumn{7}{|l|}{ Factors related to work organization } \\
\hline Paced work & & & 0.487 & & & $\mathbf{0 . 1 3 3}$ \\
\hline No & 843 & 11.0 & & 633 & 20.1 & \\
\hline Yes & 89 & 13.5 & & 52 & 28.9 & \\
\hline Work pace dependent on automatic rate & & & 0.841 & & & 0.061 \\
\hline No & 835 & 11.1 & & 638 & 19.9 & \\
\hline Yes & 93 & 11.8 & & 48 & 31.3 & \\
\hline Work pace dependent on other technical organization & & & 0.260 & & & 0.184 \\
\hline No & 688 & 10.6 & & 608 & 20.1 & \\
\hline Yes & 241 & 13.3 & & 75 & 26.7 & \\
\hline Work pace dependent on quantified targets & & & 0.378 & & & 0.081 \\
\hline No & 448 & 10.3 & & 426 & 18.5 & \\
\hline Yes & 488 & 12.1 & & 257 & 24.1 & \\
\hline Work pace dependent on demand of customers & & & 0.576 & & & 0.218 \\
\hline No & 512 & 11.7 & & 377 & 22.3 & \\
\hline Yes & 426 & 10.6 & & 319 & 18.5 & \\
\hline Work pace dependent on permanent controls or surveillance & & & 0.310 & & & 0.581 \\
\hline No & 710 & 10.7 & & 526 & 20.3 & \\
\hline Yes & 220 & 13.2 & & 161 & 22.4 & \\
\hline Job/task rotation ( $\geq 1$ job rotation per week) & & & 0.348 & & & 0.310 \\
\hline No & 558 & 12.0 & & 441 & 19.7 & \\
\hline Yes & 341 & 10.0 & & 225 & 23.1 & \\
\hline Overtime hours & & & 0.592 & & & 0.836 \\
\hline No & 299 & 11.7 & & 323 & 20.7 & \\
\hline Yes & 636 & 10.5 & & 373 & 20.1 & \\
\hline High visual demand & & & 0.622 & & & 0.061 \\
\hline No & 769 & 11.2 & & 575 & 19.3 & \\
\hline Yes & 172 & 9.9 & & 123 & 26.8 & \\
\hline Lack of prior information regarding the amount of work to be & lone ea & ch day & 0.189 & & & 0.347 \\
\hline No & 818 & 10.6 & & 681 & 20.3 & \\
\hline Yes & 123 & 14.6 & & 25 & 28.0 & \\
\hline Variable weekly working time & & & 0.642 & & & 0.283 \\
\hline No & 403 & 11.7 & & 359 & 18.9 & \\
\hline Yes & 542 & 10.7 & & 342 & 22.2 & \\
\hline Work with temporary workers & & & 0.613 & & & 0.470 \\
\hline No & 683 & 11.4 & & 512 & 19.9 & \\
\hline Yes & 263 & 10.3 & & 192 & 22.4 & \\
\hline Temporary employment & & & 0.867 & & & 0.087 \\
\hline No & 868 & 11.1 & & 622 & 19.6 & \\
\hline Yes & 77 & 11.7 & & 83 & 27.7 & \\
\hline \multicolumn{7}{|l|}{ Working postures and biomechanical constraints } \\
\hline High repetitiveness of tasks ( $\geq 4 \mathrm{~h} /$ day) & & & 0.388 & & & 0.039 \\
\hline No & 764 & 10.6 & & 508 & 18.7 & \\
\hline Yes & 179 & 12.9 & & 194 & 25.8 & \\
\hline High perceived physical exertion & & & 0.028 & & & $<0.001$ \\
\hline No & 753 & 10.0 & & 575 & 17.6 & \\
\hline Yes & 193 & 15.5 & & 129 & 34.1 & \\
\hline Arms above the shoulder & & & 0.041 & & & 0.073 \\
\hline No & 581 & 9.5 & & 491 & 18.7 & \\
\hline Yes & 363 & 13.8 & & 215 & 24.7 & \\
\hline
\end{tabular}




\begin{tabular}{|c|c|c|c|c|c|c|}
\hline Arms abducted ( $\geq 2 \mathrm{~h} /$ day) & & & 0.884 & & & 0.530 \\
\hline No & 822 & 11.2 & & 624 & 20.2 & \\
\hline Yes & 121 & 10.7 & & 82 & 23.2 & \\
\hline Holding hand behind the trunk ( $\geq 2 \mathrm{~h} /$ day) & & & $0.051^{\dagger}$ & & & 0.393 \\
\hline No & 907 & 10.7 & & 677 & 20.2 & \\
\hline Yes & 36 & 22.2 & & 30 & 26.7 & \\
\hline Use of vibrating handtools ( $\geq 2 \mathrm{~h} /$ day) & & & 0.716 & & & $0.249^{\dagger}$ \\
\hline No & 785 & 11.0 & & 685 & 20.3 & \\
\hline Yes & 159 & 12.0 & & 19 & 31.6 & \\
\hline Exposure to cold temperature ( $\geq 4 \mathrm{~h} / \mathrm{day})$ & & & 0.529 & & & 0.190 \\
\hline No & 875 & 11.3 & & 679 & 20.2 & \\
\hline Yes & 68 & 8.8 & & 26 & 30.8 & \\
\hline \multicolumn{7}{|l|}{ Psychosocial factors at work } \\
\hline High psychological demand & & & 0.778 & & & 0.337 \\
\hline No & 504 & 10.9 & & 372 & 21.8 & \\
\hline Yes & 435 & 11.5 & & 329 & 18.8 & \\
\hline Low decision latitude & & & 0.949 & & & 0.006 \\
\hline No & 537 & 11.2 & & 296 & 15.5 & \\
\hline Yes & 398 & 11.3 & & 404 & 24.0 & \\
\hline Low supervisor support & & & 0.915 & & & 0.614 \\
\hline No & 566 & 11.3 & & 448 & 19.9 & \\
\hline Yes & 370 & 11.1 & & 242 & 21.5 & \\
\hline Low coworker support & & & 0.414 & & & 0.081 \\
\hline No & 762 & 10.6 & & 566 & 19.3 & \\
\hline Yes & 172 & 12.8 & & 126 & 26.2 & \\
\hline
\end{tabular}

${ }^{*} \chi^{2}$ test. ${ }^{\dagger}$ Fisher exact test. ${ }^{\star}$ RPE Borg scale $\geq 15$ for men and $\geq 14$ for women.

Table 3. Multivariate model for risk factors of incidence of shoulder pain in the male and female working populations

\begin{tabular}{|c|c|c|c|c|c|c|c|c|c|c|c|c|}
\hline & \multicolumn{6}{|c|}{ Men $(\mathrm{n}=944 ; 105$ incident SP) } & \multicolumn{6}{|c|}{ Women $(\mathrm{n}=688 ; 142$ incident SP) } \\
\hline & $\mathrm{n}$ & $\%$ & OR & $95 \%$ & CI & $p$ & $\mathrm{n}$ & $\%$ & OR & $95 \%$ & CI & $p$ \\
\hline Age & & & & & & 0.001 & & & & & & 0.001 \\
\hline$<30$ & 198 & 7.1 & 1 & & & & 143 & 14.0 & 1 & & & \\
\hline $30-39$ & 292 & 8.2 & 1.2 & 0.6 & 2.4 & & 222 & 17.1 & 1.6 & 0.8 & 2.9 & \\
\hline $40-49$ & 279 & 12.2 & 2.0 & 1.0 & 3.8 & & 210 & 25.2 & 2.9 & 1.6 & 5.3 & \\
\hline$\geq 50$ & 175 & 18.9 & 3.3 & 1.7 & 6.5 & & 113 & 27.4 & 2.9 & 1.5 & 5.8 & \\
\hline BMI & & & & & & & & & & & & 0.010 \\
\hline Underweight-normal $(<25)$ & & & & & & & 498 & 18.1 & 1 & & & \\
\hline Overweight (25-30) & & & & & & & 129 & 22.5 & 1.1 & 0.6 & 1.7 & \\
\hline Obesity $(\geq 30)$ & & & & & & & 61 & 37.7 & 2.5 & 1.4 & 4.5 & \\
\hline Temporary employment & & & & & & & & & & & & 0.016 \\
\hline No & & & & & & & 607 & 19.8 & 1 & & & \\
\hline Yes & & & & & & & 81 & 27.2 & 2.1 & 1.1 & 3.7 & \\
\hline Arms above the shoulder & & & & & & 0.073 & & & & & & \\
\hline No & 581 & 9.5 & 1 & & & & & & & & & \\
\hline Yes & 363 & 13.8 & 1.5 & 1.0 & 2.3 & & & & & & & \\
\hline High perceived physical exertion* & & & & & & 0.075 & & & & & & $<0.001$ \\
\hline No & 751 & 10.0 & 1 & & & & 562 & 17.8 & 1 & & & \\
\hline Yes & 193 & 15.5 & 1.6 & 1.0 & 2.5 & & 126 & 33.3 & 2.2 & 1.4 & 3.5 & \\
\hline Low decision latitude & & & & & & & & & & & & 0.031 \\
\hline No & & & & & & & 290 & 15.9 & 1 & & & \\
\hline Yes & & & & & & & 398 & 24.1 & 1.6 & 1.0 & 2.3 & \\
\hline
\end{tabular}

$*$ RPE Borg scale $\geq 15$ for men and $\geq 14$ for women.

\section{Change of job during follow-up}

Seventy-four percent of men did not change their jobs during the follow-up period, $18.0 \%$ had changed jobs and $8.0 \%$ were unemployed. The corresponding values for women were $73.0,14.2$ and $12.8 \%$, respectively. Change of job during the follow-up period was not associated with incidence of SP in either univariate analyses or final multivariate models.

\section{Discussion}

This prospective study showed the multifactorial origin of incident SP and highlighted a limited number of individual and work-related risk factors, which differed according to gender. 
The incidence of SP was higher in women than in men. The same result was found in previous studies $^{5,7,8,12)}$. This can be explained by the differences in exposure at work and/or at home, differences in muscle strength and/or psychosocial risk factors such as low social support and perceived stress ${ }^{18,25,26)}$.

The strongest predictor of incident SP for both genders was age. This is consistent with what is known regarding the occurrence of "normal" degenerative changes in aging rotator cuff tendons ${ }^{27)}$. However, age was correlated with length of service, and we cannot exclude the possible effect of cumulative exposure to biomechanical factors. Age has been reported to be associated with prevalent shoulder pain in the literature. The results are highly contrasted in studies on the incidence of $\mathrm{SP}^{5,26)}$, age being reported as a risk factor in some studies ${ }^{5,7)}$ and not in others ${ }^{9,11)}$. Certain surveys studied biomechanical and/or psychosocial factors adjusted for age and did not reach a conclusion regarding the effect of age on incidence of $\mathrm{SP}^{8,10)}$.

Our study found an association between obesity and incident SP among women. Some epidemiological studies have reported an association with overweight and obesity ${ }^{2,5)}$, while others have not ${ }^{6,28)}$. Rechardt et $a l .{ }^{29)}$ recently reported that waist circumference and waist-to-hip ratio were associated with shoulder pain.

Among the work-related factors, working with arms above the shoulders was a risk factor for men. This is consistent with the literature ${ }^{6,9,30-32)}$, and several biomechanical mechanisms support this finding. The main pathophysiological mechanisms are compression of the tendons between the humeral head and the coracoacromial arch and ischemia due to impingement or increased intramuscular pressure following extreme arm abduction ${ }^{18,27)}$. Some conflicting results have been reported. Leclerc et al. ${ }^{6}$ ) found a significant result for women, whereas Miranda et al. ${ }^{5)}$ found that this factor was not significant in the final model. A prospective study of newly employed workers showed that working with hands above the shoulders was predictive of new onset shoulder pain (adjusted for gender) ${ }^{9)}$. For both genders, a high perceived physical exertion was associated with incident SP. This could be explained by high shoulder force requirements, which can cause increased muscle contraction activity and lead to an increase in the muscle fatigue and tensile force of the tendon ${ }^{30}$. Some similar results have been published ${ }^{5,9,28,30)}$, but assessment of exposure is diverse.

For women, low decision latitude was a risk factor for incident SP. There is evidence that psychosocial factors play a role in shoulder pain ${ }^{43,34)}$. However, no single factor has been implicated in particular ${ }^{30,33)}$. Ostergren et al. ${ }^{8}$ found that decision latitude was not associated with increased risk of suffering neck and shoulder pain during follow-up but found an association with job strain, whereas Leclerc et al. showed that a low level of job control affected the incidence of $\mathrm{SP}^{6}$. Other studies have reported job demands $\mathrm{s}^{7}$, or mental stress ${ }^{5)}$ as risk factors.

Our study failed to reveal an association between SP and factors related to the work organization, but several variables related to the technical aspects of the work organization were associated with SP in the univariate analysis for women. Since the organization of technical processes and workstations has a major influence on mechanical exposure, it can be hypothesized that the relationships between SP and such factors could have been masked by the higher and more direct association between SP and mechanical factors.

Prospective studies on incident SP have been published over the past ten years ${ }^{2,5-12)}$. The population studied has often been specific, thus preventing generalization of results. Our prospective study involved a broad sample of workers and was characterized by a wide variety of activity sectors and occupations, representing a wide range of occupational tasks.

However, some methodological issues should be discussed. The use of the term "incidence" is not completely correct. In our study, an incident case was defined as worker with shoulder pain at follow-up who had no shoulder pain at baseline, so cases occurring between the two data collections and which were negative at follow-up were not considered as incident cases.

The response rate among contactable subjects seems satisfactory, in view of the time between the two surveys ( 2 to $7 \mathrm{yr}$ ). This was due to the significant work of updating the addresses of the workers included in 2002-2005, first through their OPs and then through the postal services (more than 300 were found by this way), and also to the repeated reminders. We found significant differences between the responders and the non-responders. Men, young workers, temporary workers, low-level white collar and unskilled workers less often responded to the follow-up questionnaire. The overrepresentation of women, managers, professionals and technicians among the responders is a common result in the literature involving health questionnaires ${ }^{35)}$. Having a history of UE-MSDs or pain in an upper limb or the back at baseline had a positive impact on participation in the follow-up for men, whereas health problems in general are often reported in the literature to have a negative impact. The fact that UE-MSDs are a common and fairly minor health problem might explain why subjects without a UE-MSD (maybe feeling less affected by the study) less often partici- 
pated a few years after their inclusion in the study, as reported in women by Goldberg et al. in a French cohort $^{36)}$. This lower participation would result in an overestimation of risks of UE-MSDs only if participation is higher among workers exposed to UE-MSDs than others ${ }^{37)}$. In our study, a higher level of initial exposure may have positively influenced participation of both genders, as found elsewhere ${ }^{38}$. The difference in percentages of exposure factors was nevertheless low between responders and non-responders. Moreover, a study on the impact of loss to follow-up in epidemiological studies on UE-MSDs ${ }^{38}$ ) found that the differences in the characteristics between participants and those lost to follow-up did not influence the risk ratios for associations between exposure factors for UE-MSDs and UE-MSD status. We therefore believe that there is no major selection phenomenon associated with the quality of the follow-up.

We chose to define SP as that occurring during the preceding 7 days to limit memory bias. For the group without SP at baseline, we excluded workers with SP of more than 8 days during the preceding 12 months or with SP during the preceding 7 days. We studied shoulder pain by means of a self-reported questionnaire, the Nordic questionnaire, which is the most widely used questionnaire to collect musculoskeletal

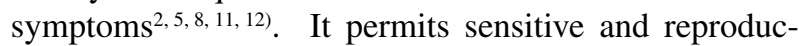
ible assessment of the prevalence and incidence rates of musculoskeletal symptoms ${ }^{16}$.

A self-administered questionnaire was also used to assess the work-related factors. Stock et al. ${ }^{39)}$ showed there is no perfect instrument for measuring dimensions of physical load. Self-reported measures offer the possibility to survey a large sample of workers that includes a wide variety of job titles and hence occupational tasks. Assessment of occupational factors was requested for a typical workday in the preceding 12-month period, and awkward postures were presented in picture form to facilitate workers' understanding and increase the validity of selfassessment of posture. Furthermore, as far as possible, standardized and validated instruments were used such as the European consensus for biomechanical factors and the Karasek Job Content Questionnaire for psychosocial factors ${ }^{20,24)}$.

Some studies have reported sport as a risk factor for incident $\mathrm{SP}^{5,7,12,14)}$. Miranda et al. showed that some sports activities such as jogging decreased the risk of shoulder pain, whereas dancing increased the risk of shoulder pain ${ }^{5}$. In a review of factors associated with MSDs, Malchaire et al. ${ }^{26)}$ showed that there was a lack of significance for hobbies and sports. Muscles and tendons are not stressed in the same way according to the sport, and questions should be more specific because information was often vague in questionnaires. A more recent study showed that life events were related to the occurrence of incident neck/ shoulder pain (for example, entering a new permanent relationship with a partner or changing workplace, profession or employer $)^{40)}$. Due to the length of our self-administered questionnaire, we preferred not to ask questions about sports, hobbies, life events or depressive symptoms. Although non-work activities may represent important confounders in our study, we believe that their influence is probably not sufficient to affect the value of the study.

In conclusion, this study showed that incident SP was related both to individual and work-related factors and differed according to gender. The effect of age was greater than that of other factors. However, in contrast to work-related factors, age is not modifiable. Mechanical and psychosocial exposure should therefore be an important target for strategies for the prevention of shoulder pain in the working population.

Acknoledgments: This project was supported by grants from the French Institute for Public Health Surveillance, Saint-Maurice, France (grant 9/25/2002-5 "Réseau expérimental de surveillance des troubles musculo-squelettiques"), and the French National Research Agency (ANR-grant SEST-06-36). We thank the occupational physicians involved in the baseline sentinel network: Doctors Abonnat, Banon, Bardet, Becquemie, Bertin, Bertrand, Bidron, Biton, Bizouarne, Boisse, Bonamy, Bonneau, Bouguer-Diquelou, Bourrut-Lacouture, Breton, Caillon, Cesbron, Chisacof, Chotard, Compain, Coquin-Georgeac, Cordes, Couet, Coutand, Danielou, Darcy, Davenas, De Lansalut, De Lescure, Diquelou, Dopsent, Dufrenne-Benetti, Dupas, Evano, Fache, Fontaine, Frampas-Chotard, Guillier, Guillimin, Harinte, Harrigan, Hervio, Hirigoyen, Jahan, Jube, Kalfon, Labraga, Laine-Colin, Laventure, Le Dizet, Lechevalier, Le Clerc, Ledenvic, Leroux, Leroy-Maguer, Levrard, Levy, Logeay, Lucas, Mallet, Martin-Laurent, Mazoyer, Meritet, Michel, MigneCousseau, Moisan, Page, Patillot, Pinaud, Pineau, Pizzalla, Plessis, Plouhinec, Raffray, Robin-Riom, Roussel, Russu, Saboureault, Schlindwein, Soulard, Thomson, Treillard and Tripodi. The authors declare that they have no conflicting or competing interests. The authors are responsible for the content and writing of the paper.

\section{References}

1) Ha C, Roquelaure $Y$, Leclerc $A$, Touranchet $A$, Goldberg M, Imbernon E. The French musculoskeletal disorders surveillance program: pays de la Loire network. Occup Environ Med 2009; 66: 471-9. [PubMed] [CrossRef]

2) Luime JJ, Kuiper JI, Koes BW, Verhaar JAN, 
Miedema HS, Burdorf A. Work-related risk factors for the incidence and recurrence of shoulder and neck complaints among nursing-home and elderlycare workers. Scand J Work Environ Health 2004; 30: 279-86. [PubMed] [CrossRef]

3) Roquelaure $\mathrm{Y}, \mathrm{Ha} \mathrm{C}$, Leclerc $\mathrm{A}$, et al. Epidemiologic surveillance of upper-extremity musculoskeletal disorders in the working population. Arthritis Rheum 2006; 55: 765-78. [PubMed] [CrossRef]

4) van der Windt DA, Thomas E, Pope DP, et al. Occupational risk factors for shoulder pain: a systematic review. Occup Environ Med 2000; 57: 433-42. [PubMed] [CrossRef]

5) Miranda H, Viikari-Juntura E, Martikainen R, Takala EP, Riihimäki H. A prospective study of work related factors and physical exercise as predictors of shoulder pain. Occup Environ Med 2001; 58: 528-34. [PubMed] [CrossRef]

6) Leclerc A, Chastang J-F, Niedhammer I, Landre M-F, Roquelaure Y. Incidence of shoulder pain in repetitive work. Occup Environ Med 2004; 61: 39-44. [PubMed] [CrossRef]

7) Cassou B, Derriennic F, Monfort C, Norton J, Touranchet A. Chronic neck and shoulder pain, age, and working conditions: longitudinal results from a large random sample in France. Occup Environ Med 2002; 59: 537-44. [PubMed] [CrossRef]

8) Ostergren P-O, Hanson BS, Balogh I, et al. Incidence of shoulder and neck pain in a working population: effect modification between mechanical and psychosocial exposures at work? Results from a one year follow up of the Malmö shoulder and neck study cohort. J Epidemiol Community Health 2005; 59: 721-8. [PubMed] [CrossRef]

9) Harkness EF, Macfarlane GJ, Nahit ES, Silman AJ, McBeth J. Mechanical and psychosocial factors predict new onset shoulder pain: a prospective cohort study of newly employed workers. Occup Environ Med 2003; 60: 850-7. [PubMed] [CrossRef]

10) Andersen JH, Kaergaard A, Mikkelsen S, et al. Risk factors in the onset of neck/shoulder pain in a prospective study of workers in industrial and service companies. Occup Environ Med 2003; 60: 649-54. [PubMed] [CrossRef]

11) Smedley J, Inskip H, Trevelyan F, Buckle P, Cooper C, Coggon D. Risk factors for incident neck and shoulder pain in hospital nurses. Occup Environ Med 2003; 60: 864-9. [PubMed] [CrossRef]

12) Siivola SM, Levoska S, Latvala K, Hoskio E, Vanharanta H, Keinänen-Kiukaanniemi S. Predictive factors for neck and shoulder pain: a longitudinal study in young adults. Spine 2004; 29: 1662-9. [PubMed] [CrossRef]

13) da Costa BR, Vieira ER. Risk factors for work-related musculoskeletal disorders: a systematic review of recent longitudinal studies. Am J Ind Med 2010; 53: 285-323. [PubMed] [CrossRef]

14) Viikari-Juntura E, Shiri R, Solovieva S, et al. Risk factors of atherosclerosis and shoulder pain - Is there an association? A systematic review. Eur J
Pain 2008; 12: 412-26. [PubMed] [CrossRef]

15) Crawford JO. The Nordic musculoskeletal questionnaire. Occupational Med 2007; 57: 300-1. [PubMed] [CrossRef]

16) Descatha A, Roquelaure Y, Chastang JF, et al. Validity of Nordic-style questionnaires in the surveillance of upper-limb work-related musculoskeletal disorders. Scand J Work Environ Health 2007; 33: 58-65. [PubMed] [CrossRef]

17) Franzblau A, Salerno DF, Armstrong TJ, Werner RA. Test-retest reliability of an upper-extremity discomfort questionnaire in an industrial population. Scand J Work Environ Health 1997; 23: 299-307. [PubMed] [CrossRef]

18) Hagberg M, Silverstein B, Wells R, et al. Work related musculoskeletal disorders (WMSDs): a reference book for prevention. London: Taylor \& Francis; 1995. [PubMed] [CrossRef]

19) Palmer KT, Reading I, Linaker C, Calnan M, Coggon D. Population-based cohort study of incident and persistent arm pain: role of mental health, self-rated health and health beliefs. Pain 2008; 136: 30-7. [PubMed] [CrossRef]

20) Sluiter JK, Rest KM, Frings-Dresen MH. Criteria document for evaluating the work-relatedness of upper-extremity musculoskeletal disorders. Scand J Work Environ Health 2001; 27: 1-102. [PubMed] [CrossRef]

21) Borg G. Psychophysical scaling with applications in physical work and the perception of exertion. Scand J Work Environ Health 1990; 16: 55-8. [PubMed] [CrossRef]

22) Daniels C, Huang GD, Feuerstein M, Lopez M. Self-report measure of low back-related biomechanical exposures: clinical validation. J Occup Rehabil 2005; 15: 113-28. [PubMed] [CrossRef]

23) Jang R, Karwowski W, Quesada PM, et al. Biomechanical evaluation of nursing tasks in a hospital setting. Ergonomics 2007; 50: 1835-55. [PubMed] [CrossRef]

24) Niedhammer I, Chastang JF, Gendrey L, David S, Degioanni S. [Psychometric properties of the French version of Karasek's «Job Content Questionnaire » and its scales measuring psychological pressures, decisional latitude and social support: the results of the SUMER]. Sante Publique 2006; 18: 413-27. [PubMed] [CrossRef]

25) Silverstein B, Fan ZJ, Smith CK, et al. Gender adjustment or stratification in discerning upper extremity musculoskeletal disorder risk? Scand J Work Environ Health 2009; 35: 113-26. [PubMed] [CrossRef]

26) Malchaire J, Cock N, Vergracht S. Review of the factors associated with musculoskeletal problems in epidemiological studies. Int Arch Occup Environ Health 2001; 74: 79-90. [PubMed] [CrossRef]

27) Järvholm U, Styf J, Suurkula M, Herberts P. Intramuscular pressure and muscle blood flow in supraspinatus. Eur J Appl Physiol Occup Physiol 1988; 58: 219-24. [PubMed] [CrossRef] 
28) Miranda H, Viikari-Juntura E, Heistaro S, Heliövaara M, Riihimäki H. A population study on differences in the determinants of a specific shoulder disorder versus nonspecific shoulder pain without clinical findings. Am J Epidemiol 2005; 161: 847-55. [PubMed] [CrossRef]

29) Rechardt M, Shiri R, Karppinen J, Jula A, Heliövaara M, Viikari-Juntura E. Lifestyle and metabolic factors in relation to shoulder pain and rotator cuff tendinitis: a population-based study. BMC Musculoskelet Disord 2010; 11: 165. [PubMed] [CrossRef]

30) Bernard B. Musculoskeletal disorders and workplace factors. A critical review of epidemiologic evidence for work-related musculoskeletal disorders of the neck, upper-extremity, and low back. Cincinnati (OH): DHHS (NIOSH) Publication; 1997.[PubMed] [CrossRef]

31) Niedhammer I, Landre MF, Leclerc A, et al. Shoulder disorders related to work organization and other occupational factors among supermarket cashiers. Int J Occup Environ Health 1998; 4: 168-78. [PubMed] [CrossRef]

32) Pope DP, Silman AJ, Cherry NM, Pritchard C, Macfarlane GJ. Association of occupational physical demands and psychosocial working environment with disabling shoulder pain. Ann Rheum Dis 2001; 60: 852-8. [PubMed] [CrossRef]

33) Bongers PM, Ijmker S, van den Heuvel S, Blatter BM. Epidemiology of work related neck and upper limb problems: psychosocial and personal risk factors (part I) and effective interventions from a bio behavioural perspective (part II). J Occup Rehabil 2006; 16: 279-302. [PubMed] [CrossRef]

34) van den Heuvel SG, van der Beek AJ, Blatter
BM, Hoogendoorn WE, Bongers PM. Psychosocial work characteristics in relation to neck and upper limb symptoms. Pain 2005; 114: 47-53. [PubMed] [CrossRef]

35) Goldberg M, Luce D. Les effets de sélection dans les cohortes épidémiologiques. Nature, causes et conséquences. Rev Epidemiol Sante Publique 2001; 49: 477-92. [PubMed] [CrossRef]

36) Goldberg M, Chastang JF, Leclerc A, et al. Socioeconomic, demographic, occupational, and health factors associated with participation in a long-term epidemiologic survey: a prospective study of the French GAZEL cohort and its target population. Am J Epidemiol 2001; 154: 373-84. [PubMed] [CrossRef]

37) Frost P, Bonde JPE, Mikkelsen S, et al. Risk of shoulder tendinitis in relation to shoulder loads in monotonous repetitive work. Am J Ind Med 2002; 41: 11-8. [PubMed] [CrossRef]

38) Bildt C, Alfredsson L, Punnett L, Theobald H, Torgén M, Wikman A. Effects of drop out in a longitudinal study of musculoskeletal disorders. Occup Environ Med 2001; 58: 194-9. [PubMed] [CrossRef]

39) Stock SR, Fernandes R, Delisle A, Vézina N. Reproducibility and validity of workers' self-reports of physical work demands. Scand J Work Environ Health 2005; 31: 409-37. [PubMed] [CrossRef]

40) Skillgate E, Vingård E, Josephson M, Theorell T, Alfredsson L. Life events and the risk of low back and neck/shoulder pain of the kind people are seeking care for: results from the MUSIC-Norrtalje casecontrol study. J Epidemiol Community Health 2007; 61: 356-61.[PubMed] [CrossRef] 